\title{
Goebbels Liderliğinde Nazi Almanyası'nda Propaganda Sineması
}

The Propaganda Cinema under Goebbels' Leadership in The Nazi Germany

\section{Caner Çakı ${ }^{1}$ - Mehmet Ali Gazi - Gül Çakı ${ }^{3}$ - Öğr. Gör. Dr. Fulya Almaz ${ }^{4}$}

Başvuru Tarihi: 05.09.2019

Kabul Tarihi: 26.12.2019

\section{Öz}

Nasyonal Sosyalist Alman İşçi Partisi'nin (NSDAP) 30 Ocak 1933 tarihinde iktidara gelmesi ile birlikte Almanya'da Halkı Aydınlatma ve Propaganda Bakanlığı kurulmuştu. NSDAP lideri Adolf Hitler, kurulan bu yeni bakanlığın başına partisinin önde gelen isimlerinden Joseph Goebbels'i getirmişti. Goebbels, bakanlığın başına geçtikten kısa bir süre sonra ülkedeki tüm medya kuruluşları üzerinde sıkı bir denetim kurma yoluna gitmişti. Goebbels, medya üzerinde kurulan sıkı denetim sayesinde, ülkedeki tüm kitle iletişim araçlarını Nazi rejiminin propaganda faaliyetleri için kullanmayı hedeflemişti. Özellikle bu aşamada sinema, Goebbels'in en önemli propaganda araçlarından bir haline gelmişti. Goebbels, Nazizm ideolojisinin kitleler üzerinde tahakküm kurabilmesinde sinemanın etkili bir propaganda aracı olacağına inanmıştı. Bundan dolayı Goebbels, propaganda bakanı olarak görev aldiğı 12 yıl boyunca (1933-1945), Almanya'da dünya tarihinin en etkili propaganda filmlerinin çekilmesini sağlamıştı. Çalışmada Goebbels'in bakanlĭ̆ı döneminde Almanya'da sinema sektörünün gelişim süreci, uygulanan sansürler, boykotlar, yaşanan krizler, devlet teşvikleri ve Nazi rejimi tarafindan çekilen propaganda filmleri detaylı bir şekilde açıklanmaya çalışılmıştır. Çalışma kapsamında propaganda sinemasının dönüm noktalarından biri olan Goebbels liderliğindeki Alman sinemasına ışık tutulması amaçlanmıştır.

Anahtar Kelimeler: Sinema, Propaganda, Nazi Almanyası, Naziler, Film

\section{Abstract}

The Ministry of Public Lighting and Propaganda was established in Germany, when the National Socialist German Workers' Party (NSDAP) came to power on January 30, 1933. Adolf Hitler appointed Joseph Goebbels, one of the leading figures in his party, as minister to the ministry. Shortly after he took over the ministry, Goebbels assumed control over all media outlets in the

\footnotetext{
${ }^{1}$ İnönü Üniversitesi, İletişim Fakültesi, caner.caki@inonu.edu.tr, ORCID: 0000-0002-1523-4649

${ }^{2}$ Trabzon Üniversitesi, İletişim Fakültesi, mehmetaligazi@hotmail.com, ORCID: 0000-0002-9239-4187

${ }^{3}$ Atılım Üniversitesi Halkla İlişkiler ve Reklamcılık Anabilim Dalı Yüksek Lisans Mezunu, gulcaki06@hotmail.com, ORCID: 0000-00015501-0191

4 Akdeniz Üniversitesi Sosyal Bilimler MYO, fulyaalmaz@akdeniz.edu.tr, ORCID: 0000000215373278
} 
country. Goebbels sought to use all the mass media in the country for the propaganda activities of the Nazi regime, because of the strict control over the media. Especially at this stage, cinema became one of the most important propaganda tools for Goebbels. Goebbels believed that cinema would be an effective propaganda tool for Nazism ideology to dominate the masses. Therefore, Goebbels made the most effective propaganda films in world history during the 12 years he served as propaganda minister in Germany. In the study, the development process of cinema sector in Germany, censors, boycotts, crises, government incentives and propaganda films made by the Nazi regime were tried to be explained in detail. The aim of the study is to give information on German cinema led by Goebbels, one of the turning points of the propaganda cinema.

Keywords: Cinema, Propaganda, Nazi Germany, Nazis, Film

\section{Giriş}

20. yüzyılın ilk yarısı sinemanın yoğun olarak propaganda amaçlı kullanıldığı bir dönem olmuştur. Bu dönemde birbirleri ile rekabet içerisinde olan Komünizm, Faşizm, Nazizm, Falanjizm gibi ideolojiler sinemayı kitleler üzerinde belirli bir etki oluşturmak ve kendi söylemlerini meşrulaştırmak amacıyla kullanmıştır. Çekilen propaganda filmleri, belirli bir siyasi görüş üzerinden izleyiciyi ikna etmek ve izleyicinin görüşlerini etkilemek için üretilmiştir. Propaganda filmleri, dönemin egemen ideolojileri tarafından üretilen yapay gerçeklikleri doğal gerçeklikler olarak inşa etmek amacıyla kullanılmıştır. Böylece egemen güçler, propaganda filmleri yoluyla kitlelerin duygularına hitap etmeyi ve istenilen ideolojik söylemleri kitlelere empoze etmeyi amaçlamıştır.

Propaganda filmlerinin ilk başarılı örnekleri Birinci Dünya Savaşı'nda üretilmeye başlanmıştır. $\mathrm{Bu}$ dönemde savaşan taraflar, halklarına kendilerini güçlü göstermek ve düşmanlarını itibarsızlaştırmak amacıyla kısa propaganda filmleri çekmiştir. Bu filmlerin başında 1918 ABD yapımı Özgür Olmak İstiyorsan Sam Amca'yı Destekle (Stake Uncle Sam to Play Your Hand) adlı propaganda filmi gelmiştir. Filmde ABD propagandası tarafından Alman İmparatorluğu'na karşı nefret söylemi inşa edilerek Amerikan halkının savaşta desteğinin alınması amaçlamıştır. Film, ilerleyen dönemde çekilecek propaganda filmleri için öncü nitelik taşımış ve sinemanın propaganda amaçlı kullanılabileceği fikrinin gelişmesini sağlamıştır. Aynı dönemde ABD sinemasında, Küçük Amerikalı (The Little American, 1917), Inanılmaz (The Unbeliever, 1917), Almanya'da Dört Yılım (My Four Years in Germany, 1918), Dünya'nın Kalpleri (Hearts of the World, 1918) adlı propaganda filmleri de çekilmiştir. Tüfek Omza (Shoulder Arms, 1918) adlı propaganda filminde de dönemin ABD'li sessiz sinema yıldızı Charlie Chaplin baş rol oynamıştır (Lemaster, 1997, s.112).

Birinci Dünya Savaşı'ndan sonra propaganda sinemasının Sovyetler Birliği'nde gelişme gösterdiği görüşmüştür. Sovyet sinemasında çekilen propaganda filmleri özellikle Komünizm ideolojisinin yüceltilmesine ve Sovyet liderleri Vladimir Lenin ve Joseph Stalin'in kült liderlik imajının güçlendirilmesine hizmet etmiştir. Bu filmler içerisinde 1925 yllında çekilen Potemkin 
Zırhlssı (Броненосец Потёмкин), dünya tarihinin ilk profesyonel sinema tekniklerinin kullanıldığı propaganda filmlerinden biri olmuştur (Patalas, 2005, s.30). Film dönemin teknik imkanları gereği sessiz film olarak çekilmiş ve 1905 yılında Çarlık rejimine karşı ayaklanan denizcileri konu almıştır. Mosfilm (Мосфи́льм) tarafından yapılan filmde, Sovyet yönetimi Rus halkının Çar'ın ordusuna karşı mücadelesi ile 1917 Ekim Devrimi'nde verilen mücadele arasında bağ kurmayı ve böylece filmin devrim propagandası haline gelmesini amaçlamıştır. Sovyetler Birliği'nde ilerleyen süreçte Dünya (Земля, 1930), Denizlerin En Mavisi'nden (У самого синего моря, 1936), Bezhin Meadow (1937), Yemin (Клятва, 1938), Berlin'in Düşüşü (Падение Берлина, 1950) adlı propaganda sinemasında kült haline gelecek olan filmler çekilmiştir. Berlin'in Düşüşü filminde, hem Nazi Almanyası ağır bir dille eleştirilmiş hem de Sovyetler Birliği lideri Joseph Stalin'in kült liderlik propagandası yapılmıştır (Michaels, 2008, s.212).

Sinemanın propaganda açısından devrim niteliğinde yenilikler ile tanışması, Nazi Almanyası döneminde (1933-1945) gerçekleşmiştir. Almanya'da propaganda sineması, Nazilerin iktidara geldiği 1933 yllına kadar gelişmemiştir. Bunun temel nedeni Birinci Dünya Savaşindan sonra Almanya'da kurulan Weimar Cumhuriyeti'nin (1919-1933), 1919 yılında imzaladığı Versay Antlaşması hükümleri gereği İtilaf Devletleri ile dostane bir şekilde ilişkileri sürdürmesi olmuştur. Nitekim bu dönemde Almanya'nın saldırgan bir dış siyaset izlemesine izin verilmemiştir. Diğer yandan Almanya'nın İtilaf Devletleri'ne ödediği savaş tazminatı, yaşanan ekonomik sıkıntılar ve işsizlik gibi nedenler Alman sinemasının gelişmesi için önemli engeller teşkil etmiş̧ir. Buna karşın 1920'li yılların başından itibaren Alman siyaset sahnesinde yer almaya başlayan antisemitist, antikapitalist ve antikomünist fikirlere sahip aşırı milliyetçi Nasyonal Sosyalist Alman İşçi Partisi (NSDAP), sinemanın propaganda faaliyetlerindeki öneminin farkına varmış ve propaganda sinemasının geliştirilmesinde öncü rol oynamıştır. Özellikle partinin Berlin Gauleiter'i ${ }^{5}$ Joseph Goebbels, sinemanın kitlelerin ideolojik fikirlerini etkilemede çok etkili olduğu görüşünü savunmuştur. Goebbels'in bu görüşü NSDAP'nin Almanya'da iktidara gelmesinden sonra da devam etmiş ve Goebbels tarafindan Alman sineması NSDAP'nin propaganda faaliyetlerine hizmet eder hale getirilmiştir. Goebbels'in sinemayı propaganda amaçlı kullanma fikri, Hitler tarafından da desteklenmiş ve Goebbels tarafından hazırlatılan propaganda filmlerine büyük mali yardım yapılmıştır. Bu süreçte Goebbels, ülkede kurulan resmi sinema teşkilatları ile sinema sektörü üzerinde kontrolü elde etmiş, aynı zamanda Alman yönetmen Leni Riefenstahl gibi profesyonel isimler ile çalışarak dünya tarihinin en etkili propaganda filmlerinin çekilmesi sağlamıştır. Nazi Almanyası'nda bu dönemde İrade'nin Zaferi (Der Sieg des Glaubens, 1933), Özgürlüğün Günü: Wehrmacht'ımız (Tag der Freiheit: Unsere Wehrmacht, 1935), Jud Süß (1940), Ebedi Yahudi (Der ewige Jude, 1940), Polonya'ya Sefer (Feldzug in Polen, 1940), Führer'e Yürüyüş (Der Marsch zum Führer, 1940), Rothschildler (Die Rothschilds, 1940), Bati'da Zafer (Sieg im Westen, 1941), Kolberg (1945) adlı propaganda filmleri çekilmiştir.

Goebbels'in teşviki ile sinemada pek çok yenilik uygulamaya sokulmuş, Alman sineması dönemin en prestijli Amerikan filmleri ile boy ölçüşebilecek noktaya gelmiştir. Buna karşın

${ }^{5}$ Belirli bir bölgenin kontrolünü üstlenen, Hitler tarafından atanan ve yine Hitler tarafından görevden alınan NSDAP yöneticisi. 
hazırlanan filmlerin önemli bir kısmında Nazi rejiminin ve Nazizm ideolojisinin doğrudan propagandasına yer verilmiş, Alman sinemasının propaganda kavramı ile özdeşleştirilmesine yol açılmıştır. Çalı̧̧ma kapsamında Goebbels'in propaganda bakanlığı döneminde Alman sinemasına ışık tutulmaya çalışılmış, böylece Goebbels'in liderliğinde sinemanın etkin bir propaganda aracı olarak kullanılabilmesi için hangi evrelerden geçildiğinin açıklanması amaçlanmıştır.

\section{NSDAP Iiktidarından Önce Alman Sineması}

Almanya'da sinemanın tarihi Max Skladanowsky ve Emil Skladanowsky kardeşler tarafından 1 Kasım 1895 tarihinde gerçekleştirilen kısa film gösterisi ile başlamıştı (Eisner, 2008, s.7). Skladanowsky kardeşler tarafından hazırlanan kısa film gösterisinin ardından Alman sineması, Guido Seeber ve Oskar Messter gibi Alman yapıcıların katkıları ile hızlı bir gelişim sürecine girmişti. Almanya'da üretilen filmlerin yanında çeşitli Avrupa ülkelerinden de film ithal edilmeye başlanmıştı. Filmlerin bu dönemde sessiz olması, dil sorunun oluşmasını engellemiş ve farklı ülkelerde de filmlerin izlenebilme olanağının oluşmasını sağlamıştı. 1910'lu yıllardan itibaren Almanya'da ilk profesyonel filmler çekilmeye başlanmıştı. Özellikle Stellan Rye ve Paul Wegener yönetmeliğindeki Der Student von Prag (Prag'ın Öğrencisi, 1913) adlı uzun metrajlı film, Alman sinemasında yaşanan gelişimin mihenk taşı olarak ön plana çıkmıştı (Bär, 2005, s.552). Bu dönemde Alman seyircisi tarafından büyük ilgi gören filmlerin devamı niteliğindeki filmler çekilmiş ve zaman içerisinde Almanya'da dizi-film kültürü oluşmaya başlamıştı. Aynı yıllarda Alman sinemasının ilk sinema yıldızları da ortaya çıkmışıı. Sinema yıldızları, Alman toplumunun sosyal hayatında önemli fenomenler haline gelmiş ve kimi yıldızlar Alman vatandaşları için kült kişiliklere dönüşmüştü.

Alman İmparatorluğu'nun 1914 yllında İtilaf Devletleri'ne karşı Birinci Dünya Savaşı'na girmesinden sonra Alman sinemasında köklü değişiklikler yaşanmıştı. Almanya ilk olarak savaş halinde olduğu ülkelerin filmlerini boykot ederek ülkede yayınlanmasına izin vermemişti. Daha sonra 1917 yılında Alman film şirketi Universum Film AG (UFA) kurulmuştu. UFA'nın kurulması, Alman propaganda sinemasının da miladı olmuştu. Almanya, İtilaf Devletleri'nin propaganda filmlerine yönelik olarak UFA bünyesinde karşı propaganda filmleri hazırlamaya başlamıştı. Bu aşamada UFA'ya doğrudan Alman hükümetinin müdahalesi söz konusu olmuştu. UFA bünyesinde uzun metrajl, belgesel formatında propaganda filmlerinin çekilmesi planlamıştı. Buna karşın 1918 yılında Almanya'nın Birinci Dünya Savaşıı'nda ayrılmasıyla birlikte planlanan propaganda filmlerinin çekilmesi mümkün olmamıştı. 1920'li yıllarında başında UFA özelleştirilmiş ve başlangıçtaki amacından farklı olarak propaganda filmleri yerine eğlence filmleri üretmeye başlamıştı. Alman sinemasında eğlence filmlerinin yanı sıra suç ve macera konuları da ön plana çıkmıştı. Bu süreç Alman sinemasında hızlı bir gelişimin yaşanmasını sağlamıştı. Almanya genelinde yüzlerce sinema filmi çekilmiş, binlerce sinema salonu açılmış ve milyonlarca sinema izleyicisine ulaşılmıştı. Diğer yandan filmlerin profesyonelleşme süreci bu dönemde de devam etmiş, UFA'da Die Nibelungen (1924) ve Faust (1926) gibi önemli yapıtlar üretilmişti. Die Nibelungen, bir Orta Çağ destanını konu edinmişti (Hauer, 1990, s.103). UFA, Amerika Birleşik Devletleri'nde bulunan Hollywood filmlerine rakip olabilecek noktaya gelmişti (Frodon, 1998, s.71). Diğer yandan bu dönemde Alman filmleri yurt dışına ihraç edilmeye başlanmıştı. 
1920'li yıllarda ülke çapında üretilen filmlerin kontrolünü sağlamak için Weimar Cumhuriyeti'nde* kanun çıkarılmıştı. Yine bu dönemde filmler üzerinde sansür uygulamasına gidilmişti. Weimar Cumhuriyeti'nde, kamu düzenini ve güvenliğini tehdit edebilecek, Almanya'nın itibarını veya Almanya'nın yabancı devletlerle olan ilişkilerini tehlikeye sokabilecek veya moral bozucu olabilecek, dini duyarlılığı ihlal edebilecek filmler kontrol altına alınmıştı. Bu dönemde Almanya'nın bozulan ekonomik yapısı ve artan işsizlik Alman sinemasında eğlence türü filmlerin yanında, toplumsal içerikli filmlerin de çekilmesine yol açmıştı. Filmlerde Alman halkının yaşadığı günlük sorunlara farklı açılardan değinilmişti. Toplumsal içerikli bu filmleri içerisinde Berlin'de lüks otellerinden birinin üniformalı kapıcısını konu alan Friedrich Wilhelm Murnau'nun yönetmenliğindeki Der Letzte Mann (Son Adam, 1924) adlı psikolojik film uluslararası alanda önemli başarılara imza atmıştı. Ayrıca 1932 yılında Almanya'da gerginleşen siyasi atmosferde sosyalist propaganda filmi Slatan Dudow yönetmenliğinde Kuhle Wampe adlı film yayınlanmıştı (Birgel, 2009, s.40). Film, yayınlandığı yıl Almanya' da cumhurbaşkanı, hukuk sistemi ve dini olumsuz yönde resmettiği yönündeki suçlamalar nedeniyle yasaklanmış, buna karşın alınan kararın aleyhine yapılan protestoların ardından yasak kaldırılmıştı. Aynı dönemde Gustav Ucicky yönetmenliğindeki Das Flötenkonzert von Sans-souci (1930) gibi sağ muhafazakar filmler de Alman sinemasında yerini almaya başlamıştı. Bu süreç sinemada politik söylemlerin etkili olmaya başlamasına neden olmuştu. Diğer yandan Almanya'nın zaman içerisinde film ihracatındaki gelirlerinde de önemli bir artış gerçekleşmişti. Bu aşamada ihraç edilen filmler Alman ekonomisi için önemli bir gelir kaynağı haline gelmişti.

1930'lu yıllardan itibaren sesli filmler Almanya'da da etkili olmaya başlamıştı. Sesli filmlerin çekilmesi ilk başlarda Alman filmlerinin ihracatında olumsuz bir etki meydana getirmişti. Nitekim filmlerin sesli olmasıyla birlikte Alman filmlerinin hitap ettiği izleyici kitlesi yalnızca Almanca konuşulan ülke ve bölgeler ile sınırlı kalmıştı. Bunun yanında eşzamanlı olarak hem Almanca hem de İngilizce olarak çekilen Josef von Sternberg yönetmenliğindeki Der blaue Engel (Mavi Melek, 1930) sesli filmi uluslararası alanda önemli başarılara imza atmış, filmin oyuncusu Marlene Dietrich'in de dünya çapında büyük bir ün elde etmesini sağlamıştı (Koch, 1986, s.65).

\section{Goebbels'in Alman Sinemasında Denetim Kurması}

1920'li yılların başında Weimar Cumhuriyeti'nde aşırı sağ görüşlü Nasyonal Sosyalist Alman İşçi Partisi (NSDAP) etkili olmaya başlamıştı. Antikapitalist, antisemitist, antikomünist ve Alman milliyetçiliğine dayalı Nazizm ideolojisini benimseyen NSDAP, 1929 Dünya Ekonomik Buhranı sürecinde Almanya'da yaşanan ekonomik krize çözüm bulmak vaadiyle 30 Ocak 1933 tarihinde Almanya'da iktidara gelmeyi başarmıştı. NSDAP lideri Adolf Hitler, Alman şansölyesi olmasından sonra Almanya'da Halkı Aydınlatma ve Propaganda Bakanlığı'nı kurmuş ve kurulan bakanlığın başına da NSDAP'nin propaganda sorumlusu ve yakın dostu Dr. Joseph Goebbels'i getirmişti. Goebbels, propaganda bakanı olduktan sonra ülkedeki tüm kitle iletişim araçlarını denetimi altına almış ve ülke genelinde NSDAP'nin yoğun bir şekilde propaganda

\footnotetext{
* Birinci Dünya Savaşı'ndan sonra Almanya'da kurulan ve NSDAP'nin 1933 yılında iktidara gelmesinden sonra ortadan kaldırılan Alman cumhuriyeti.
} 
faaliyetlerine girişmişti. Goebbels'in propaganda bakanlığının temel amacı NSDAP'nin Nazizm ideolojisine dayalı söylemlerini ve otoritesini tüm Almanya'da egemen kılmaya çalışmaktı. Goebbels, dönemin önde gelen kitle iletişim araçları gazete, dergi, poster ve radyoyu propaganda faaliyetlerinde etkili bir şekilde kullanmıştı. Bu aşamada Goebbels, özellikle sinemayı propaganda faaliyetleri için önemli bir araç olarak değerlendirmekteydi. Filmin önemli bir propaganda aracı olduğu, partinin kurulduğu dönemden beri hakim bir görüştü. Ancak filmin propagandasında çok az finansmana ve deneyime sahipti. Parti tarafından üretilen filmler amatördü ve çoğunlukla kapalı parti toplantılarına gösterilmişti (Welch ve Winkel, 2011, s.1).

Goebbels'e göre sinema kitlelere belirli bir fikir veya düşüncenin empoze edilmesinde çok etkili bir araç görevi üstlenmekteydi. Bu amaçla Goebbels, Alman sineması üzerinde sıkı bir denetim kurmayı ve akabinde ülke genelinde Nazizm ideolojisini ve NSDAP'yi yücelten propaganda filmlerini çekmeyi planlamıştı. Goebbels sinema üzerinde faaliyetleri zaman içerisinde dünya tarihinin en etkili propaganda filmlerinin yapımına yol açacaktı. Diğer yandan sinemaya olan katkıları nedeniyle Goebbels, bulunduğu dönemde Alman filmlerinin hamisi (Schirmherrn des deutschen Films) olarak adlandırılacaktı. Goebbels'in bakanlığı Alman film endüstrisi üzerinde büyük bir etkiye sahip olmuştu (Schütz, 1995, s.140).

Goebbels liderliğindeki Alman sinemasında genel olarak filmlerin kontrolü, sansürü ve aryanlaştırılması üzerine odaklanılmıştı. Goebbels'in filmleri, doğrudan Nazi rejiminin propagandasına yönelmişti. Buna karşın propaganda filmleri üzerinde temkinli davranan Goebbels, Alman sinemasının tümünde propaganda filmlerinin hakim olmasından kaçınmıştı. Goebbels'in propaganda filmleri, Alman eğlence filmlerinin yanında oldukça sınırlı sayıda üretilmişti (Demetz, 2005, s.137). Filmlerde NSDAP'yi yansıtan sembol ve organizasyonlara nadiren yer verilmişti. Goebbels'in propaganda film üretiminde Das Amt Film önemli bir görev üstlenmişti. Das Amt, NSDAP'nin her yll gerçekleşen Nürnberg Parti Mitingleri'nin 1927 yılında ilk propaganda filmi olan Eine Symphonie des Kampfwillens (Savaş Arzularının Bir Senfonisi) adlı filmi çekmişti. NSDAP'nin iktidara gelmesinde sonra ise Das Amt Film'in bünyesinde bulundurduğu en son teknoloji ekipmanlar ve yüzlerce ses film aracı ile Almanya'nın en ücra köşesine kadar Nazi propaganda filmlerinin ulaşmasını sağlamıştı. Bu aşamada Das Amt Film tarafından Juden ohne Maske (Maskesiz Yahudi, 1937), Sowjet-Paradies (Sovyet Cenneti, 1942) gibi kısa propaganda belgeselleri çekmişti. Sowjet-Paradies filminde doğrudan Sovyetler Birliği'ne karşı olumsuz bir propagandaya yönelinmişti (Lorenz, 2016, s.121). Filmlerde Yahudilik ve Bolşevizm'e karşı sert söylemlere yer verilmişti.

NSDAP'in Alman sinemasında kontrol kurabilmesini sağlamak için Halkı Aydınlatnma ve Propaganda Bakanlığı Film Bölümü ve Reichsfilmkammer (Reich Film Odası, RFK) olmak üzere iki resmi birim meydana getirmişti (Padover, 1939, s.143). Diğer yandan propaganda filmlerinin çekiminde Reichskulturkammer (Reich Kültür Odası, RKK) ve NSDAP Reich Propaganda Müdürlüğü'nün Amt Filmi de etkili olmuştu. NSDAP tarafından tüm bu birimlerin başına tam yetkili olarak Goebbels getirilmişti. 
Almanya'daki tüm kültürel çalışmaların denetlenmesinden sorumlu olan RKK, Alman filmlerinin denetiminde de ön plana çıkmıştı. Almanya'da bulunan tüm sanatçıların RKK'ya üye olması zorunluluğu getirilmişti. Böylece RKK üzerinden kültürel faaliyette bulunan her vatandaşın doğrudan kontrol edilmesi amaçlanmıştı. Diğer yandan Nazi rejiminin politikası gereği RKK bünyesine Aryan olmayanların kabul edilmesine izin verilmemişti. Bu süreç Almanya'da başta Yahudiler olmak üzere aryan olarak görülmeyen tüm grupların kültürel çalışmalardan soyutlanmasına neden olmuştu. Goebbels'in bakanlığı, yasalarla yetkilendirilmişti (Dahm, 1986, s.68). Goebbels, RKK bünyesinde sözde Entartete Kunst'a (Yozlaşmış Sanat) karşı mücadele içerisine girmişti. Goebbels'e göre modern sanat olarak adlandırılan ABD ve Sovyetler Birliği merkezli sanatta yenileşme hareketine karşı çıkılmıştı. Bu süreçte Goebbels daha çok gelenekselliği, ırksal saflı̆̆ı, militarizmi, itaati, kan ve toprak değerlerini yücelten sanat eserlerinin ön plana çıkarılmasını amaçlamıştı. Goebbels, Yahudi yapımcıları Alman sinemasından dışlamıştı (Horak ve Bishop, 1996, s.373). Goebbels tarafından karşı çıkılan yozlaşmış sanat söylemi, Almanya'da film ve oyunların sansürlenmesine neden olmuştu. Goebbels, komünizm ideolojisinin propagandasının yapıldı̆̆ı ve Kulturbolschewismus (Kültür Bolşevizm'i) olarak adlandırılan yönetmen, oyuncu ve filmlerin de Alman sinemasından uzaklaştırılmasına yol açmıştı.

RFK'nın denetimi de Alman sineması üzerinde önemli bir etkiye sahip olmuştu. Almanya'da film prodüksiyonu, dağıtımı ve sinema alanlarındaki her türlü faaliyette yer alanlar, RFK'ya bağlı olmak zorunda bırakılmıştı (Witte, 1993, s.120). RFK böylece film endüstrisinde çalışanları kontrol etmenin yanı sıra, istenmeyen kişileri dışlamak için de görev yapmıştı. RFK'ya kayıt olmak için başvuranların sadece siyasi geçmişleri hakkında değil, aynı zamanda "irksal" ve "dinsel" konular hakkında da bilgi vermesi gerekmişti. Başvuru sahibinin "Yahudi" veya bir sol parti üye olmuş olması başvurusunun reddine yol açmıştı. RFK, doğrudan devlet adına kontrol hakkına sahip olmuştu (Wright, 2011, s.266). Diğer yandan bazı istisnalarda söz konusu olabilmekteydi. Politik olarak herhangi bir yerde bağı olmayan ya da önceki filmleri Nazizm'den sapmış olan ancak sanatsal ve ticari olarak çok başarılı olan bazı yönetmenlerin Nazi rejimine sadık olmaları müddetçe çalışmalarına izin verilmişti. Bu süreçte yönetmenlerin Nazizm ideolojisi ile bağlantılı bir filmi sahnelemesi istendi. Yöneticiler istenileni yerine getirdikleri taktirde kariyerine Almanya'da devam edebilmekteydi. Aksi halde kariyerleri sona ermiş oluyordu.

Goebbels tarafından 4 Temmuz 1938 tarihinde profesyonel sinema eğitimi verilmesi amacıyla Babelsberg Alman Film Akademisi (Deutsche Filmakademie Babelsberg) kurulmuştu. Babelsberg, doğrudan devlet tarafından yönetilen ilk Alman film eğitim merkezi olmuştu. Reich Eğitim ve Propaganda Bakanlı̆̆g'nın Film Bölümü'ne bağlı olan kurum film yönetmenleri, senaristler, yapım yöneticileri, kameramanları ve film mimarları için bir eğitim merkezi olarak hizmet vermişti. Okulda belgesel ve haber filmleri ile ilgili seminerler yapılmıştı (Hochscherf ve Vande Winkel, 2016, s.196). Eğitim dört yarıyıldan fazla sürmekte ve uzun metrajlı bir filmin çekimi ile tamamlanmaktaydı. Öğrenci olarak kaydolmak isteyen adayların "aryan kökenli" olduklarını ve NSDAP'a olan ilişkilerini kanıtlamaları gerekiyordu. Başlangıçta kuruma önemli miktarda fon sağlanmıştı. Buna karşın İkinci Dünya Savaşı'nın başlamasından sonra kurum çok 
maliyetli kabul edildi ve Goebbels tarafından savaş süresince kapatılmıştı. 1944 yılında da tamamen dağılmıştı.

Alman sinema endüstrisi 1930'ların ortasında en ağır krizlerinden birini yaşamaya başlamıştı. Bu krizin oluşumunda üç temel neden bulunmaktaydı; uluslararası alanda Nazi filmlerinin boykot edilmesi, film yapımcilarının ülkelerini terk etmesi ve RFK tarafından yeni filmlere uygulanan yasakçı tutum. Nazilerin baskıcı politikaları ve antisemitist faaliyetleri, uluslararası alanda büyük tepkiye neden olmuş ve Alman ürünlerinin boykotuna yol açmıştı. 1936 yılında Berlin'de gerçekleştirilen Olimpiyat Oyunları'nın bile benzer şekilde boykot edilmesi söz konusu olmuştu. Özellikle Naziler tarafından 1938 yılında gerçekleştirilen Kristal Gece

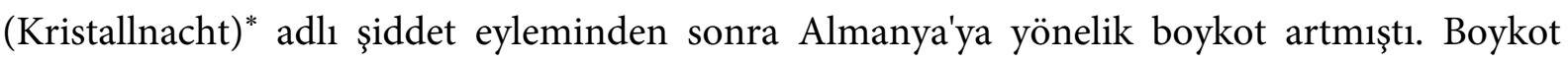
zaman içerisinde Alman sinemasını da etkilemiş, Alman filmlerinin pek çok ülkede yayınlanmasına izin verilmemesine neden olmuştu. Bu süreç Alman sineması için önemli bir gelir kaynağı olarak kabul edilen film ihracatının olumsuz yönde etkilenmesine yol açmıştı. Örneğin Leni Riefenstahl'in yönetmenliğinde büyük bir bütçe ile hazırlanan Berlin Olimpiyatları'nı konu alan Olympia filmi bu boykottan en olumsuz etkilenen filmlerin başında gelmişti (Graham, 1993, s.435). Film ihracatındaki azalma yeni filmlerin üretim maliyetlerinin karşılanmasını zorlaştırmıştı. Goebbels tarafından Nazi rejimi için tehlike oluşturacağı düşünülen veya sakıncalı olarak nitelendirilen filmlerin yasaklanması, Almanya'da film sektörünün tek bir boyutta gelişmesini ve dolayısıyla sinemada farklı görüş ve düşüncelerin ortaya konduğu filmlerin üretilmesini engellemişti. Son olarak Nazilerin iktidarından sonra Almanya'dan pek çok yapımcı, yönetmen, oyuncu ve teknik elemanın ülkeyi terk etmesi, Alman sineması için yeri doldurulamaz bir boşluğun meydana gelmesine neden olmuştu. Alman sineması için yaşanan tüm bu olumsuzluklar, pek çok film yapım şirketinin iflas etmesine yol açmıştı. Almanya'da zaman içerisinde film yapım şirketlerinin sayısı sürekli olarak azalmıştı.

Goebbels, Alman sinemasını içerisine düştüğü bu zor durumdan kurtarmak için hızla harekete geçmişti. Goebbels tarafından uygulanan politikaların temelinde Alman film endüstrisinin yeniden yapılandırılması hedeflenmişti. Goebbels'in müdahaleleri sonucunda Alman film endüstrisi bir propaganda endüstrisi haline getirilmişti. Bu amaçla Film Kredi Bankası (Filmkreditbank GmbH, FKB) kurularak, Nazi rejiminin uygun göreceği yeni filmlerin finanse edilmesi planlanmıştı (Mühl-Benninghaus, 1989, s.317). Sayısı hızla azalan film şirketlerinin daha fazla film üretmesi sağlanmıştı. Böylece ülkede film yapım şirketlerinin sayısının azalmasına rağmen üretilen film sayısında önemli bir değişiklik yaşanmamıştı. Goebbels, Cautio Treuhand $\mathrm{GmbH}$ adlı aracı şirketten yararlanarak ülkede kalan tüm film yapım şirketlerinin çoğunluk hisselerini satın almıştı. Cautio Treuhand $\mathrm{GmbH}$ görünüşte özel bir şirketti. Buna karşın Goebbels adına, 1933'ten 1942'ye kadar tüm film yapım şirketlerinin önemli bir kısmını ele geçirmişti (Kallis, 2006, s.125). Goebbels'in bu girişimi film endüstrisinin kamulaştırılma sürecini hızlandırmıştı. Goebbels, doğrudan UFA'ya bağlı olan Deutsche Filmvertriebs $\mathrm{GmbH}$ (DFV) tarafından Alman filmlerinin dağıtımını da tek elden toplamıştı. Filmlerin saklanabilmesi için iyi stoklanmış film depoları kullanılmıştı. Buna karşın yapım ve

* 1938 yılının 9 Kasım'ı 10 Kasım'a bağlayan gece Naziler tarafından Yahudiler'e âit ev, iş yeri ve sinagoglara yapılan saldırılar (Jacobs, 2008: 
dağıtım sektöründen farklı olarak, sinema salonlarında millileştirme uygulamasına gidilmemişti. Almanya sınırları içerisinde mevcut olan binlerce sinema salonu özel işletmelerin denetimine bırakılmıştı. Yine de Goebbels, bu işletmeler üzerinde de sıkı bir denetim kurmuştu. Örneğin bu sinema salonlarında Nazi rejimi tarafından önemli kabul edilen günlerde özel filmlerin gösterilmesi istenmişti. Goebbels, yabancı filmler üzerinde de denetim kurarak, kendisine yasalarca tanınan hakları kullanarak İkinci Dünya Savaşı sırasında bazı yabancı filmlerin Alman sinemasında gösterilmesini yasaklamıştı.

\section{Goebbels Liderliğinde Alman Propaganda Sineması}

Goebbels liderliğindeki Alman sinemasının temel amacı Almanların hayatının her alanında Nazi rejiminin propaganda faaliyetlerini etkin kılabilmekti. Bu amaçla eğitim ve kültür odaklı sinema filmleri, haberler ve belgesel filmleri üzerinden Alman halkına ulaşılması amaçlanmıştı.

Goebbels, propaganda sinemasının gelişmesine önemli katkılar sağlamıştı. Bu süreçte Goebbels, propaganda filmlerine geniş bir bütçe ayırmış, aynı zamanda da profesyonel isimler ile çalışma yoluna gitmişti. Goebbels, NSDAP'nin parti propaganda filmini hazırlamak için de yine geniş bir bütçe ve profesyonel bir yönetmenden yararlanmıştı. 1935 yılında Alman yönetmen Leni Riefenstahl'e Triumph des Willens (İrade'nin Zaferi) adlı propaganda filmi hazırlatmıştı. Film, 1934 yılındaki NSDAP'nin Nürnberg Parti Mitingi'ni konu almıştı (Loiperdinger, 1993, s.40). Filmde kullanılan en son teknoloji ve teknikler nedeniyle film dünya tarihinin en etkileyici propaganda filmleri arasında yer almayı başarmıştı. Filmde Hitler'in kült liderliği ön plana çıkarılırken, Nazizm ideolojisinin de kitleler nezdinde meşruluk kazanması için çalışılmıştı. Yine 1938 yılında Riefenstahl'e Nazi rejiminin yurtiçinde ve yurtdışında itibarını arttırmak için devlet tarafından iki bölümden oluşan Olympia adlı film yaptırılmıştı (McFee ve Tomlinson, 1999, s.87).

Goebbels, Nazizm ideolojisinin öğretileri içerisinde yer alan antisemitizmi de propaganda sinemasında kullanmaktaydı (Delage, 1983, s.136). Bu aşamada propaganda amaçlı çekilen bazı filmlerde doğrudan antisemitizm konu edilmişti. Bu filmlerin başında 1940 yılında çekilen Rothschilds (Rothschildler) ve Jud Süß filmler filmler gelmektedir. Filmlerde doğrudan Yahudiler hedef alınmış, Alman kamuoyunda Yahudilere yönelik olumsuz algı inşa edilmesi için çalışılmıştır. Benzer şekilde Yahudilere yönelik Alman kamuoyunda nefret söylemi oluşturmak amaciyla Juden ohne Maske (Maskesiz Yahudiler, 1937) ve Der ewige Jude (Ebedi Yahudi, 1940) adlı belgesel filmler de çekilmişti. Der ewige Jude filmi doğrudan Yahudi karşıtı bir propaganda filmi olmuştu (Friedländer, 2006, s.45). Savaşın sonlarına doğru Goebbels, Yahudileri konu alan antisemitist filmlerde önemli bir stratejik değişikliğe yönelmişti. Goebbels, 1944 yılında çekilen ve Almanya'nın denetimi altında bulunan Yahudilerin konu edildiği Theresienstadt adlı propaganda filminde, Yahudileri mutlu ve sağlıklı olarak yansıtılmıştı (Margry, 1998, s.181). Böylece Yahudilere yönelik Nazi rejimi tarafından uygulandığı belirtilen insanlık suçları ile ilgili olarak Müttefik Devletleri'ne ve tarafsı ülkelere yönelik karşı propaganda yürütülmesi amaçlanmıştı (Margry, 1992, s.150). Bu yolla Nazi rejimine karşı oluşan iddiaların itibarsızlaştırmasına çalışılmıştı. Buna karşın filmin savaşın sonlarına doğru çekilmesi ve geniş çapta dağıtılmamış olması, kamuoyunu etkileme fırsatına sahip olmasını engellemişti. 
Goebbels tarafından üniversitelerde ve okullarda kullanılmak üzere propaganda odaklı eğitim filmleri de hazırlanmıştı. Hazırlan bu filmlerde, Darwinizm, ırkçı doktrin ve anti-Semitizm gibi Nazizm ideolojinin merkezi unsurlarının doğrudan yayılması amaçlamıştı. UFA tarafından kültürel filmler de çekilmişti (Elsaesser, 1994, s.26). Sinemada geniş bir izleyici kitlesi bulan kültürel filmler de benzer propaganda amacına hizmet etmişti. Goebbels, sinemanın propaganda etkisini arttırabilmek için ülkenin en ücra köşesine kadar ulaşabilmesini hedeflemişti. Bu amaçla kırsal alanlara film programları sunabilmek için Naziler, gerekli tüm ekipmanları içeren ses filmi arabaları hazırlatmıştı. Bu arabalar Almanya'nın dört bir yanına giderek, Goebbels tarafından belirlenen herhangi bir propaganda filminin kitleler ile buluşmasını sağlayabilmekteydi. Bu gezici sinemaların yardımıyla Nazi film propagandası, daha önce hiç sinemaya gitme firsatı bulamayan izleyicilere de önemli ölçüde ulaşmıştı. Goebbels, propaganda sineması ile izleyicisi arasındaki tüm engelleri ortadan kaldırmayı hedeflemişti. Böylece sinemanın kitleler üzerindeki etkisinden yararlanarak, Nazi rejiminin Almanya'nın en ücra köşelerinde bile otorite kurmasını sağlamaya çalışmıştı.

Goebbels, Almanya'da yaşanan gelişmeler ile ilgili olarak Alman halkını bilgilendirmeyi hedeflemişti. $\mathrm{Bu}$ amaçla Propaganda Bakanlığı'ndaki Film Bölümü tarafından Deutsche Wochenschau adlı haber programı hazırlatılarak NSDAP tarafindan yapılan faaliyetler hakkında Alman halkına bilgi verilmesine başlanmıştı. Günümüzde haber programlarının temelini atan Deutsche Wochenschau çağının en son teknolojisi ile hazırlanan bir haber programıydı. Goebbels tarafından Deutsche Wochenschau'nun yapımının her aşaması izlenmekteydi. Deutsche Wochenschau periyodik aralıklarla Alman izleyicisiyle buluşmakta ve Hitler önderliğinde Almanya'da inşa edilen fabrikalardan, anma törenlerine kadar geniş bir perspektiften gündem hakkında bilgi vermekteydi. İkinci Dünya Savaşı sırasında Deutsche Wochenschau doğrudan cephelerdeki haberleri Alman halkına ulaştırmaya başlamıştı (Winkel, 2004, s.7). Savaşın başlarında Almanya'nın zaferlerini konu alan program, savaşın sonlarına doğru Müttefik Devletleri tarafından işlenen sözde insanlık suçlarını ve Alman halkının vatan savunmasını konu edinmeye başlamıştı. Özellikle Sovyetler Birliği'ne karşı olumsuz yönde propaganda yürütülmüştü (Pietrow-Ennker, 1989, s.81). Nazi propagandası, Kızıl Ordu'nun işgal ettiği yerlerde Alman kadınlarına tecavüz ettiğini belirterek, Doğu Cephesi'nde Alman halkının Kızıl Ordu'ya karşı savaşma isteğini arttırmaya çalışmıştı. Kızıl Ordu askerleri olumsuz bir alg1 içerisinde sunulmuştu (Grossmann, 1994, s.19). Deutsche Wochenschau savaş programlarında doğrudan cephelerdeki sahnelere yer vermişti. Yayınlanan programlar Alman işgal bölgesi üzerinde de etkili olmuştu. Deutsche Wochenschau yayınlarını İkinci Dünya Savaşı'nın sonuna kadar sürdürmüştü (Bucher, 1986, s.54). Deutsche Wochenschau tamamen Goebbels'in denetiminde olduğu için Nazi rejiminin istediği haberler yayınlanmakta, istemediği haberlerde yayınlanmamaktaydı. Örneğin 1943 yllında Alman general Friedrich Paulus'un Stalingrad'da ordusuyla birlikte Kizll Ordu'ya teslim olmasinın programlara konu edilmemesine izin verilmemişti. Alman ordusunun Stalingrad'da aldığı yenilginin Alman halkının morali üzerinde olumsuz bir etki meydana getirebileceği, hatta Alman halkının savaşma isteğini azaltabileceği düşünülmüştü.

Goebbels liderliğindeki Alman sinemasında pek çok farklı konu ve tema ele alınmaktaydı. Bunlardan biri de milliyetçilik temalı propaganda filmleri olmuştu. Alman sinemasında Alman 
ulusunun milliyetçi duygularına hitap eden Der alte und der junge König (Yaşlı ve Genç Kral, 1935), Pour le Mérite (1938), Kampfgeschwader Lützow (1939), Der grosse König (Büyük Kral, 1942) ve Kolberg (1945) gibi savaş filmleri çekilmişti. Kolberg filmi, Almanya'nın İkinci Dünya Savaşı'ndan yenilgiyle ayrılmasından kısa bir süre önce hazırlanmıştı (Paret, 1994, s.435). Filmlerde daha çok Nazizm ideolojisinin siyasal propagandası, Alman ulusunun yüceltilmesi, Alman halkının düşmanları ve savaş propagandası ön plana çıkarılmıştı. Filmlerde yer alan Alman tarihi şahsiyetlerinin Alman gençleri için kült kişilikler olmasına çalışılmaktaydı. Naziler tarafından çekilen tarihi filmlerde de Alman halkının geçmişteki başarılarına ve mücadeleci yapısına dikkat çekmek istemişti. Alman sinemasında çekilen filmlerin sınırlı bir kısmı doğrudan propaganda filmi olarak hazırlatılmıştı. Almanya'daki filmlerin konusunu genel olarak eğlence ve aşk içerikli filmler oluşturmaktaydı. Alman propaganda sinemasında çizgi filmde üretilmişti (Aslangul, 2008, s.16). Bunlardan bir tanesi Nazi Almanyası'nın işgali altındaki Fransa'da çekilen Nimbus Libéré isimli propaganda çizgi filmi olmuştu. Çizgi filmde Müttefik Devletleri'nin Fransa'ya yapmış oldukları hava saldırılarının sivil halka zarar verdiğgi iddia edilmiş ve Müttefik Devletleri ağır bir şekilde eleştirilmişti (Delporte, 2001, s.367). Naziler, bu süreçte uzun metrajlı filmlerin içerisinde propaganda içeren mesajları kullanmıştı. Böylece Alman halkının beğeni ile izlediği bir eğlence filminde bile Nazi propagandasının faaliyet göstermesi amaçlanmıştı. Diğer yandan Naziler, filmin kurgusu ile gelişen oyuncuların kıyafetlerine ve imajına doğrudan müdahalede bulunmamıştır. Aynı şekilde filmlerde Nazizm ideolojisi tarafından idealize edilen Alman karakterlerin konulması zorunlu tutulmamıştır. Nitekim filmlerde insanların imajı Nazizm ideolojinin gerekliliklerine nadiren uyum sağlamıştır. Kahramanların çoğu, kişisel servetleri için savaşan modern değerlere saygı gösteren, ortalama kişi tipinde olmuştur. Örneğin Nazizm ideolojisince idealize edilen çocuklarına bakan ve ev işleri ile ilgilenen Alman kadın rolü genel olarak filmlerde yer bulamamıştır. Filmlerde yer alan kadın karakterlerin çoğu çocuksuz ve bir işte çalışır vaziyette aktarılmıştır. Eğlence filmleri, savaşın son yıllarında Alman halkının yaşadığı sıkıntılardan ve günlük gerçekliklerden uzaklaştırabilmesinde önemli bir rol oynamıştı. Alman ordularının Müttefik Devletleri'ne karşı Stalingrad Savaşı'nda (1943) ve Normandiya Kuşatması'nda (1944) aldığı büyük yenilgilerden sonra Alman sineması, halkın moralini yüksek tutmak ve dikkatlerini dağıtmak amacıyla eğlence filmlerine yönelmişti. Diğer yandan Naziler, Opfergang (1944) filmi gibi melodram filmleri de çekmişti. Bu film de propaganda amacına hizmet etmişti (Kreimeier, 1994, s.50). Böylece Nazi propagandası çekilen eğlence filmleri üzerinden Almanya'nın aldığı yenilgilerin çok önemli olmadığı ve Almanya'nın hale güçlü durumda bulunduğu algılarını oluşturmaya çalışılmıştı. Bu yolla kitlelerin Nazi rejimine karşı olası muhalefetinin önlenmesi hedeflenmiști.

Goebbels, Alman sinemasını dünya genelinde marka haline getirebilmek için film yldızlarından yararlanmayı seçmişti. Bu amaçla Nazi rejiminin kendi film yıldızlarını oluşturması planlanmıştı. Alman oyuncularının sinemada yıldız haline gelebilmesinde Goebbels doğrudan rol oynamıştı. Nazi rejiminin imajını güçlendirmek için Goebbels, ylldız sisteminin gelişimini kitlesel olarak sağlamıştı. Nazi rejimine karşı eleştirilerde bulunan Heinrich George ve Gustaf Gründgens gibi oyuncular Goebbels'in işbirliği teklifini kabul etmişti. Goebbels tarafından Alman sinemasının yıldızları yeniden oluşturulmuştu. Örneğin 
İsveçli Zarah Leander Alman sinemasında yldı haline getirilen isimlerden biri olmuştu. Leander'in reklam kampanyası UFA Basın Ofisi tarafından bizzat yönetilmişti (Currid, 1998, s.61-62). Hitler ve Goebbels gibi NSDAP'nin üst düzey liderleri de kimi zaman film yıldızlarılla birlikte kitlelere aktarılmıştı. Film yıldızları NSDAP'nin imajının şekillenmesinde önemli bir rol üstlenmişti. Alman sinemasında yükselmenin en temel şartı Nazi rejimine bağlı hareket edilmesiydi. Goebbels'in direktifleri doğrultusunda hareket eden ve rejime bağlllıklarını bildiren oyuncular, film bürokrasisindeki yüksek görevlere getirilmekteydi.

İkinci Dünya Savaşı'nda Almanya'nın işgali altında olan bölgelerde film endüstrileri doğrudan Nazilerin denetimin altına girmişti. Naziler, işgal altında olan ülkelerde de sinema yoluyla propaganda faaliyetlerini sürdürmüştü. Bu ülkelerde bulunan oyuncular Nazilerin denetiminde filmlerde rol alabilmekteydi. Örneğin, Polonya film endüstrisi, Wehrmacht'ı* 1 Eylül 1939 tarihindeki işgalinden sonra varlığını sonlandırmıştı. Alman işgali ile birlikte Polonya'da film yapımı tamamen durmuştu. Diğer yandan Nazilerin işgali altında bulunan Fransa'nın kuzey bölümünde Alman haber bültenleri ve sinema filmleri bulunmaktaydı. Nazilerin kontrolü altında bulunan Fransız film yapım şirketi Continental Films, Paris bölgesindeki tüm film stüdyolarını yönetmiş ve işgal altında film üretimini sürdürmüștü (Thaisy, 2006, s.31). İşgal altındaki Norveç'in sinemasında da Naziler ile işbirliği yapanlar etkili olmuştu (Sørenssen, 2011, s.220). Naziler, Sovyetler Birliği'nde işgal ettikleri film stüdyolarında da propaganda faaliyetlerine yönelmişti. Ayrıca İkinci Dünya Savaşı sırasında Alman işgali altında bulunan ülkelere filmler ihraç edilmeye başlanmıştı. Goebbels, en zor şartlara rağmen propaganda film yapımını savaşın sonuna kadar devam ettirmişti.

\section{Sonuç}

Alman sinemasında, 1933 ylında Nazilerin iktidara gelmesinden sonra radikal değişimler yaşanmıştır. Bu süreçte Alman sineması tamamen Goebbels'in kontrolüne bırakılmış ve Alman filmleri üzerinde doğrudan Nazi rejiminin etkisi ortaya çıkmışıı. Goebbels, dönemin en son teknolojisini kullanarak, filmlerin propaganda amaçlı gücünden mümkün olduğunca etkin bir şekilde yararlanmaya çalışmıştır. Bu amaçla Almanya'nın en ücra bölgelerine kadar sinema filmlerinin ulaşmasını sağlamıştır. Goebbels'in sinema üzerindeki mutlak hakimiyeti üzerine temellenen sansür uygulaması ve sıkı denetim, Almanya'da güçlü bir propaganda sinemasının oluşmasına zemin hazırlamıştır. Nitekim Almanya'da farklı ideolojik söylemlere sahip veya Nazi rejimi için tehdit oluşturabilecek herhangi bir filmin çekilmesine izin verilmemiştir. Bu nedenle Alman sineması Nazizm temelli tek boyutlu olarak gelişim göstermiş ve çekilen filmlerde Nazi propagandasının etkisi ortaya çıkmıştır.

Goebbels, Nazi propagandasının filmler yoluyla kitlelere empoze edilmesine büyük önem vermiştir. Buna karşın doğrudan propaganda amaçlı hazırlanan filmlerin sayısı oldukça sınırlı tutulmuş, kitlelerin daha çok eğlence, komedi ve aşk filmleri içerisinde konumlandırılan propaganda çalışmaları ile etkilenmesi yoluna gidilmiştir. Diğer yandan eğlence odaklı filmler ile İkinci Dünya Savaşı'nda Almanya'nın aldığı yenilgiler de olduğu gibi kitlelerin dikkatinin farklı bir yöne çekilmesi için çalışılmıştır. Goebbels, propaganda filmlerinin hazırlanması için

\footnotetext{
* Nazi Almanyası döneminde (1933-1945) Alman ordusuna verilen isim.
} 
büyük bütçelere sahip olmuş ve dönemin en profesyonel yapımcı, yönetmen ve oyuncuları ile çalışma yoluna gitmiştir. Goebbels'in liderliğindeki Alman sinemasında özel sektörün oldukça sınırlı olduğu, hatta 1942 yılında Alman sinemasının tamamen kamulaştırıldığı görülmüştür. Bu süreçte Goebbels doğrudan filmler üzerinde propaganda amaçlı etkide bulunma olanağ etmiştir. 1930'larda yaşanan uluslararası boykotlar ve İkinci Dünya Savaşı'nın getirdiği sıkıntılara rağmen Goebbels'in desteği ile Alman sineması, ABD'deki Hollywood filmleri ile rekabet edebilecek boyutta filmler üretmeyi başarmıştı.

Goebbels'in denetiminde faaliyet gösteren Deutsche Wochenschau programları ile modern haber bültenlerinin çekirdeği oluşturulmuş ve tamamen Nazi rejimi tarafından istenen haberlerin yayınlanması sağlanmıştır. Bu programlarda doğrudan Nazi rejimi ve Nazizm ideolojisi yüceltilirken, Yahudilik ve komünizm ağır bir şekilde eleştirilmiştir. Özellikle bu programlar Goebbels tarafından İkinci Dünya Savaşı'nda, Müttefik Devletleri'ne karşı nefret söylemi inşa etmek için propaganda amaçlı kullanmıştır. Goebbels, propaganda amaçlı çekilen filmler üzerinden Alman sinemasında da Nazizm ideolojisinin antisemitist, antikomünist ve ırkçı söylemlerini ön plana çıkarmıştır. Bu yolla Nazizm ideolojisinin öğretilerini meşrulaştırmak için propaganda sinemasını bir araç olarak kullanmıştır. Goebbels, Nazi Almanyası'nın savaşta aldığı ağır yenilgilere ve Müttefik Devletleri'nin Almanya topraklarına yönelik saldırılarına rağmen savaşın son anlarına kadar propaganda filmlerinin üretimini ve propaganda programlarının yayınlanmasını sürdürmüştür.

\section{Kaynakça}

Aslangul, C. (2008). Guerre et Cinéma à L'époque Nazie. Films, Documentaires, Actualité et Dessins Animés au Service de la Propagande. Revue Historique des Armées, 252, 16-26.

Bär, G. (2005). Das Motiv des Doppelgängers als Spaltungsphantasie in der Literatur und im deutschen Stummfilm, 84. Amsterdam: Rodopi.

Birgel, F. A. (2009). Kuhle Wampe, Leftist Cinema, and the Politics of Film Censorship in Weimar Germany. Historical Reflections/Reflexions Historiques, 35(2), 40-62.

Bucher, P. (1986). Goebbels und die Deutsche Wochenschau. Nationalsozialistische Filmpropaganda im Zweiten Weltkrieg 1939-1945. Militärgeschichtliche Zeitschrift, 2, 53-69.

Currid, B. (1998). "Es war so wunderbar!" Zarah Leander, ihre schwulen Fans, und die Gegenöffentlichkeit der Erinnerung. montage AV. Zeitschrift für Theorie und Geschichte audiovisueller Kommunikation, 7(1), 57-94.

Dahm, V. (1986). Anfänge und Ideologie der Reichskulturkammer. Vierteljahrshefte für Zeitgeschichte, 34, 53-84.

Delage, C. (1983). La Vision Nazie de L'histoire: le Cinéma Documentaire du Troisième Reich. Suisse: L'Age d'homme. 
Delporte, C. (2001). Humour as a Strategy in Propaganda Film: The Case of a French Cartoon from 1944. Journal of European Studies, 31(123), 367-377.

Demetz, P. (2005). Der Prager Film in der Zeit der Okkupation 1939-1945. Transit, 30, 137154.

Eisner, L. H. (2008). The Haunted Screen: Expressionism in the German Cinema and the Influence of Max Reinhardt. The United States: Univ of California.

Elsaesser, T. (1994). Moderne und Modernisierung. Der deutsche Film der dreißiger Jahre. montage AV. Zeitschrift für Theorie und Geschichte audiovisueller Kommunikation, 3(2), 23-40.

Friedländer, S. (2006). Das dritte Reich und die Juden (Vol. 2). Deutschland: CH Beck.

Frodon, J. M. (1998). La Projection Nationale: Cinéma et Nation. France: Odile Jacob.

Graham, C. C. (1993). 'Olympia'in America, 1938: Leni Riefenstahl, Hollywood, and the Kristallnacht. Historical Journal of Film, Radio and Television, 13(4), 433-450.

Grossmann, A. (1994). Eine Frage des Schweigens: Die Vergewaltigung deutscher Frauen durch Besatzungssoldaten: Zum historischen Hintergrund von Helke Sanders Film BeFreier und Befreite. Frauen und Film, 54/55, 15-28.

Hauer, S. R. (1990). The Sources of Fritz Lang's" Die Nibelungen". Literature/Film Quarterly, 18(2), 103-110.

Hochscherf, T., \& Vande Winkel, R. (2016). Third Reich Cinema and Film Theory. Historical Journal of Film, Radio and Television, 36(2), 190-213.

Horak, J. C., \& Bishop, J. (1996). German Exile Cinema, 1933-1950. Film History, 8(4), 373389.

Jacobs, J. (2008). Memorializing the Sacred: Kristallnacht in German National Memory. Journal for the Scientific Study of Religion, 47(3), 485-498.

Kallis, A. (2006). Nazi Propaganda and 'Coordination': The Haphazard Path to Totalitarianism. European Review of History: Revue Européenne D'histoire, 13(1), 115139.

Koch, G. (1986). Zwischen den Welten: von Sternbergs "Der Blaue Engel" (1930). Frauen und Film, 41, 65-74.

Kreimeier, K. (1994). Von Henny Porten zu Zarah Leander. Filmgenres und Genrefilm in der Weimarer Republik und im Nationalsozialismus. montage AV. Zeitschrift für Theorie und Geschichte audiovisueller Kommunikation, 3(2), 41-54. 
Lemaster, D. J. (1997). The Pathos of the Unconscious: Charlie Chaplin and Dreams. Journal of Popular Film and Television, 25(3), 110-117.

Loiperdinger, M. (1993). Sieg des Glaubens. Ein gelungenes Experiment nationalsozialistischer Filmpropaganda. In Formative Ästhetik im Nationalsozialismus. Intentionen, Medien und Praxisformen totalitärer ästhetischer Herrschaft und Beherrschung, 35-48.

Lorenz, O. (2016). Die Ausstellung „Das Sowjetparadies“ : Nationalsozialistische Propaganda und Kolonialer Diskurs. Revue d'Allemagne et des Pays de Langue Allemande, 48(48-1), 121-139.

Margry, K. (1992). 'Theresienstadt'(1944-1945): The Nazi Propaganda Film Depicting the Concentration Camp as Paradise. Historical Journal of Film, Radio and Television, 12(2), 145-162.

Margry, K. (1998). Ein interessanter Vorgänger: Der erste Theresienstadt-Film (1942). Theresienstädter Studien und Dokumente, 5, 181-212.

McFee, G., \& Tomlinson, A. (1999). Riefenstahl's Olympia: ideology and aesthetics in the shaping of the Aryan athletic body. The International Journal of the History of Sport, 16(2), 86-106.

Michaels, L. (2008). Come and See (1985): Klimov's Intimate Epic. Quarterly Review of Film and Video, 25(3), 212-218.

Mühl-Benninghaus, W. (1989). The German Film Credit Bank, Inc.: Film Financing during the First Years of National-Socialist Rule in Germany. Film History, 3(4), 317-332.

Padover, S. K. (1939). The German Motion Picture Today: The Nazi Cinema. The Public Opinion Quarterly, 3(1), 142-146.

Paret, P. (1994). 'Kolberg'(1945) as Historical Film and Historical Document. Historical Journal of Film, Radio and Television, 14(4), 433-448.

Patalas, E. (2005). The Odyssey of the Battleship: On the Reconstruction of Potemkin at the Filmmuseum Berlin. Journal of Film Preservation, 70, 30-41.

Pietrow-Ennker, B. (1989). Die Sowjetunion in der Propaganda des Dritten Reiches: Das Beispiel der Wochenschau. Militärgeschichtliche Zeitschrift, 2, 79-120.

Schütz, E. (1995). Das Dritte Reich als Mediendiktatur: Medienpolitik und Modernisierung in Deutschland 1933 bis 1945. Monatshefte, 129-150.

Sørenssen, B. (2011). From Will to Reality-Norwegian Film during the Nazi Occupation, 1940-45. In Cinema and the Swastika (pp. 220-230). London: Palgrave Macmillan. 
Thaisy, L. (2006). La Politique Cinématographique de la France en Allemagne Occupée (19451949). France: Presses Univ. Septentrion.

Welch, D., \& Winkel, R. V. (2011). Europe's New Hollywood? The German Film Industry Under Nazi Rule, 1933-45. In Cinema and the Swastika (pp. 1-24)., London: Palgrave Macmillan.

Winkel, R. V. (2004). Nazi Newsreels in Europe, 1939-1945: the Many Faces of Ufa's Foreign Weekly Newsreel (Auslandstonwoche) versus German's Weekly Newsreel (Deutsche Wochenschau). Historical Journal of Film, Radio and Television, 24(1), 5-34.

Witte, K. (1993). Film im Nationalsozialismus. In Geschichte des deutschen Films (pp. 119170)., Stuttgart: JB Metzler.

Wright, R. (2011). Swedish film and Germany, 1933-45. In Cinema and the Swastika (pp. 265-275)., London: Palgrave Macmillan. 